\title{
The Influence of Family Economic Status on Literacy Ability of Early School-Aged Children: The Mediating Effect of Parental Involvement
}

\begin{abstract}
Rou Sun*
High School Affiliated to Renmin University of China, Beijing 100080, China

*Corresponding author. Email:sunrou0623@163.com

ABSTRACT

The impact of family economic status on children's development has been widely concerned in recent years. However, the influence of the basic cognitive ability of early school-aged children and its mechanism need to be further studied. In this study, 120 early school-aged children were tested with the revised "Family Economic Status Questionnaire", "Parental Involvement Questionnaire" and "Children's Literacy Ability Test", and found the mediating effect of parental involvement on the relationship between family economic status and children's literacy ability. The results showed that: (1) family economic status can positively predict the literacy ability of early school-aged children $(\mathrm{r}=0.27, \mathrm{p}<0.05)$; (2) parental involvement plays the completely mediating effect in the impact of family economic status on the literacy ability of early school-aged children.
\end{abstract}

Keywords: Family economic status, Cognitive ability of children, Parental involvement.

\section{INTRODUCTION}

Family is a unit of social life based on emotional ties and kinship. It is one of the core elements in people's social life. Family life tends to occupy a large proportion in most people's daily life. In the development of the family, the born of children is often of special significance to a family, it represents the continuation of new life and the integrity of family structure ( $\mathrm{Li}$ Yan, \& Wu Weiping, 2009). In many studies, researchers have found that family, as the main body of children's life, plays an important role in the development of children's physical and psychological abilities. In the theories, researchers believe that the family environment which has influenced on children includes subjective environment and objective environment: objective environment mainly refers to the family environment which does not take the human will as the transfer, such as family economic status, family structure, parental occupation, educational level, number of children and their birth orders. Subjective environment refers to the artificial family environment, such as parental rearing pattern, degree of parental involvement, time of company, parental expectations, family relationships and so on. They work together as a whole part for the development of children (Li Song, 2007).

\section{THE INFLUENCE OF FAMILY ECONOMIC STATUS ON CHILDREN'S DEVELOPMENT}

Family economic status has always been one of the hot topics of research. In a narrow sense, the family economic status refers to the income of the parents and the core members of the family, and in a broad sense, it includes the parental occupation, education level and other more extensive factors (Zhou Hao, 2013). In the current century, the material and economic conditions of the family largely determine the advantages and disadvantages of other factors of the family. And it will have a decisive impact on the other characteristics of the family. In addition, family economic status has a direct impact on the development of the family as a whole and every member of the family, in particular the development of the abilities of children(Conger, Conger, \& Martin, 2010). In previous studies, researchers have reached a more consistent conclusion for the impact of family economic status on children's development. Researchers found that good family economic status has a positive effect on children's academic achievement, 
educational completion, health level and the growth of social emotions and behaviors (Duncan, Brooks-Gunn, \& Klebanov, 1994; Zhou Hao, 2013; Liu Haoqiang, \& Zhang Qinglin, 2004; Bradley, \& Corwyn, 2002). However, some studies suggest that family economic status has a direct positive predictive effect for children's cognitive development. For instance, McCall (1981) suggested that the influence of family economic status on children's cognitive development originates from their early age, and poverty is positively correlated with children's low IQ and low school performance. The researchers also explored the academic performance and intelligence of children aged 3 and 7 in different families, the results showed that even at different ages, children born in high economically supportive families showed significantly higher abilities than other children (Bradley, \& Corwyn, 2002). However, in other researches, the researches found family economic status is a moderating factor. It will indirectly affect children's cognitive development by influencing other variables, such as parental involvement in education, school environment and so on (Epstein, \& Dauber, 1991). In general, the family economic status plays a positive role in the development of children's cognitive ability.

\subsection{The Influence of Parental Involvement on Children's Development}

Parental involvement is an important part of early intervention research in children development. Researchers generally believe that parental involvement is one of the characteristics of parenting. It refers to the process of parents fulfilling their roles and promoting optimal children development, including emotional input and parental involvement in the process of children development. Different researchers have different criteria for the operational definition of parental involvement. Some refers to the monitoring and mentoring of children's learning activities by parents at home, some refers to the time and degree of parental involvement in school activities, and others refers to parents' expectations of their children's academic performance(Li Yanfang, Guan Yijie, Lou Chunfang, et al, 2005). But generally speaking, researchers believe that parental involvement usually includes: material upbringing, spiritual companionship, learning activities, communication activities and other factors closely related to the growth and development of children. Previous studies on parental involvement in children's ability development have found that the higher the level of parental involvement, the higher the children's academic performance(Henderson, 1981), and their learning potential will be higher, their self-concept will be more complete, and they may even promote the development of their interpersonal skills(Li Yanfang, Guan Yijie, Lou Chunfang, et al, 2005).
As for the antecedents factors of parental involvement, the research pointed out that the degree of parental involvement is affected by the family economic status. The better the family economic status is, the higher the degree of parental involvement will be (Hickman, Greenwood, \& Miller, 1995). Therefore, one of the topics to be discussed in this study is that whether parental involvement will be affected by the family economic status, and then affect the development of children's cognitive ability.

\subsection{The Ability of Children's Literacy}

The ability of literacy is the first cognitive ability of children's development. Literacy refers to the ability to recognize words of independent units in a text. It Is the basis for children to read, understand and even other complex cognitive activities. It can help children learn the pronunciation and meaning of words in the process of development, and they can gradually form the understanding of sentences, and finally acquire the ability of reading comprehension (Li Hong, \& Shu Hua, 2009; Galda, 2011). Children's ability of literacy is very important. Because in this period, children's thinking is characterized by specific image thinking. And when the children develop other core cognitive abilities, they need to be exposed to a large number of abstract words(Jin Xingming, 2003). Strong ability of literacy can help children have a better grasp of language, and thus they can make a faster transition to other core competencies.

However, there are not many studies have focused on the impact of family economic status on children's literacy and the researches concerned more on the development of children's reading comprehension ability. For example, the research suggested that the better the family economic status is, the lower the detection rate of dyslexia among children will be (Song Ranran, \& Wu hansong, 2008). Qin and Ge (2011) found that family economic status has an effect on the students' choice of reading materials, and then influence their reading scores. But

In recent years, researchers put forward to the simple reading view suggests that in the process of reading, the complex cognitive activity, children actually involve two core components: relatively independent decoding and speech comprehension. Among them, decoding ability is what we call literacy ability. The study found that the ability of literacy has a strong interpretation rate of children's reading comprehension ability below the third grade of primary school, and with the decrease of age, the intensity of interpretation increases gradually(Yan Mengge, Li Hong, Hui Yi, et al, 2017). In the current study, some researchers have begun to focus on the more specific variable of literacy development. But there is a lack of strong empirical support for the related factors of early childhood ability of literacy. Language communication is everywhere in 
children development and family life. Therefore, another topic of concern in this study is that whether the ability of literacy, as a cognitive ability closely related to language communication, will be affected by family economic status.

Focusing on the impact of family economic status on early childhood ability of literacy can be more effective in helping caregivers and educators to focus on early childhood development. So that we can reduce the limitations on children's future ability development due to family economic status, and propose more targeted education goals and measures to development of children.

\subsection{Hypothesis}

The purpose of this study is to explore the influence of family economic status on children's ability of literacy and the mechanism of parental involvement. Therefore, the study assumes that:

Hypothesis 1: Family economic status is positively related to the literacy ability of children in early school age;

Hypothesis 2: Parental involvement shows the mediating effect in the positive correlation between family economic status and the literacy ability of children in early school age.

\section{METHODS}

\subsection{Participants}

In this study, 125 students in 1-3 grades were selected from 3 primary schools in Beijing. There were 120 valid questionnaires, and the effective recovery rate was $96 \%$. The age of the participants are from 5 years old to 8 years old $(M=6.70, S D=1.49)$, among them, there are 58 boys $(48.3 \%)$, and 62 of them are girls $(51.7 \%)$. There are 35 of them are in the first grade $(29.2 \%), 46$ of them are in the second grade $(38.3 \%)$, and the third grade is $39(32.5 \%)$.

When we selected the participants, the teaching skills quality and teaching environment of the selected schools are in the same level. The students' family in three selected school are all including low-income families, general families and high-income families. In defining the screening criteria for family economic status, this study refers to the national economic income and living expenditure standards of China. The families with monthly total income above 20000 yuan are classified as high-income families, the families with monthly total income of 6000-2000 yuan are classified as general families, and the families with monthly total income below 6000 yuan are classified as low-income families.

\subsection{Measures}

We used questionnaires to measure students' family economic status, parental involvement and children's literacy ability. The questionnaires include the revised "Family Economic Status Questionnaire", "Parental Involvement Questionnaire" and "Children's Literacy Ability Test".

Family Economic Status Questionnaire was compiled according to "Questionnaire of Family Economy” that revised by Sun Bei (2019).

The questionnaire surveyed 9 items about children's demographic information and family economic status, including their age, sex, grade, family composition, parental education and family economic status, and there are 3 items relate to their family economic status. The total monthly income of the family is arranged according to "2000 yuan below", "2000-6000 yuan", "6000-10000 yuan", "10000-200000 yuan", "20000 yuan above", all items are scored from 1 to 5 . The SES (socio-economic status) of the family is scored on a ten-point scale. The family's monthly economic investment in the development of children's literacy ability is arranged according to "less than 50 yuan", "50-100 yuan", "100-500 yuan", "500-1000 yuan", "1000-2000 yuan", "2000-5000 yuan", " more than 5000 yuan", all items are scored from 1 to 7 . So the score range of family economic status is between 3 and 22, and the higher the score is, the better the family economic status is. In this study, the Cronbach' $\alpha$ coefficient was 0.80 .

Parental Involvement Questionnaire that was used in this study was based on the revised Parental Involvement Questionnaire by Liu(2019). The questionnaire included three dimensions: "home-school contact", "school involvement" and "home involvement", with 20 items. According to the purpose of this study, this study selected 7 items in the dimension of "home involvement", and it is scored on a five-point scale. the Cronbach' $\alpha$ coefficient was 0.89 . It has good validity in the group of children's parents and is suitable for investigating the parental involvement in the process of children's development in China.

Children's Literacy Ability Test was revised from the "Primary School Language Reading Proficiency Assessment Scale" which was compiled by Wen (2005). We selected a 600-word fables as the reading material. And under the assessment of two PhDs in the field of development education for young children and one Master of Chinese Language and Literature, we selected 10 words, such as "愣", "骇人", "参差不齐" and so on in the article. We want to test whether the participants identified the words presented. If they recognize it correctly, they would score 1 point, and if they don't recognize, they would not score it. So children's literacy ability scores range from 0 to 10 , the higher the score is, 
the stronger the literacy is. Then five comprehension questions were added to test whether children read carefully, which was not included in the total score as one of the screening criteria. In this study, the Cronbach' $\alpha$ coefficient was 0.78 .

\subsection{Procedure}

This study uses a web - based questionnaire. We distributed the questionnaire to the parents of each class in grade 1-2, and asked the parents to fill out the first part of the questionnaire, including "Family Economic Status Questionnaire" and "Parental Involvement Questionnaire". And then the parents accompany the students to finish the second part. When children finish to read the article, parents as observer judge the accuracy of children's answers. Then the researchers selected the non-standard or random questionnaire, and finally obtained 120 valid questionnaires.

\section{RESULTS}

\subsection{Overall family Economic Status, Parental Involvement and Literacy Ability of Children in Early School Age}

Descriptive statistics of the data obtained from the three questionnaires are shown in Table1.

Table 1. Overall family economic status, parental involvement and literacy ability of children in early school age

\begin{tabular}{|c|c|c|c|}
\hline & $N$ & $M$ & $S D$ \\
\hline Family economic & 120 & 12.74 & 2.99 \\
status & 120 & 19.57 & 8.38 \\
Parental involvement & 120 & 4.95 & 3.17 \\
Literacy ability & & & \\
\hline
\end{tabular}

\subsection{Correlation Analysis of the Family Economic Status, Parental Involvement and Literacy Ability of Children in Early School age}

We used correlation analysis for the measured data, and the results are shown in Table2.

Table 2. Correlation analysis of family economic status, parental involvement and literacy ability of children in early school age

\begin{tabular}{|c|c|c|c|}
\hline Variable & $\begin{array}{c}\text { Family } \\
\text { economic } \\
\text { status }\end{array}$ & $\begin{array}{c}\text { Parental } \\
\text { involvement }\end{array}$ & $\begin{array}{c}\text { Literacy } \\
\text { ability }\end{array}$ \\
\hline $\begin{array}{c}\text { Family economic } \\
\text { status } \\
\text { Parental } \\
\text { involvement } \\
\text { Literacy ability }\end{array}$ & $\begin{array}{c}- \\
0.25^{*} \\
0.27^{*}\end{array}$ & $0 . \overline{-} * *$ & - \\
\hline
\end{tabular}

Note. $* \mathrm{p}<0.05, * * \mathrm{p}<0.01, * * * \mathrm{p}<0.001$.

We can learn from theTable2 that there was a significant positive correlation between family economic status, parental involvement and children's literacy ability. This result can verifies hypothesis 1 that family economic status can positively predict the literacy ability of children in early school age.

\subsection{Analysis of the Mediating Effect of Family Economic Status, Parental Involvement and Literacy in Early School-age Children}

To further explore the mediating effect between family economic conditions, parental involvement and children's literacy ability, we used mediating effect analysis to determine independent variable as family economic status (X), mediating variable as parental involvement $(\mathrm{M})$, dependent variable as children's literacy ability (Y), and then establish the mediation model, analyzing the mediating effect of parental involvement between family economic status and children's literacy ability. Based on Amos software, average coefficient and model fitting index of the mediation model are analyzed, and they are shown in Table 3 and Table 4.

Table 3. Model path coefficients for parental involvement between family economic status and literacy ability

\begin{tabular}{|c|c|c|}
\hline Path coefficient & Path coefficient & Path coefficient \\
\hline Family economic status $\rightarrow$ Parental & Family economic status $\rightarrow$ Literacy & Parental involvement $\rightarrow$ Literacy \\
involvement & ability & ability \\
$0.27 *$ & 0.01 & $0.94 * * *$ \\
\hline
\end{tabular}

Note. $* \mathrm{p}<0.05, * * \mathrm{p}<0.01, * * * \mathrm{p}<0.001$

Table 4. Test for mediation model of parental involvement

\begin{tabular}{|c|c|c|c|c|c|c|c|}
\hline $\begin{array}{c}\text { Model } \\
\text { indicators }\end{array}$ & $x^{2}$ & $d f$ & $x^{2} / d f$ & $G F I$ & CFI & AGFI & RMSEA \\
\hline & 279.98 & 3 & 93.32 & 0.90 & 1 & 0.93 & 0.062 \\
\hline
\end{tabular}


Table 5. A Bootstrap analysis of the significance test of the mediating effect of parental involvement between family economic status and literacy ability

\begin{tabular}{|c|c|c|c|c|c|c|}
\hline $\begin{array}{c}\text { Independent } \\
\text { variable }\end{array}$ & $\begin{array}{c}\text { Mediating } \\
\text { variable }\end{array}$ & $\begin{array}{c}\text { Dependent } \\
\text { variable }\end{array}$ & $\begin{array}{c}\text { Indirect effects of } \\
\text { standardization }\end{array}$ & $\begin{array}{c}\text { Average } \\
\text { indirect effects }\end{array}$ & \multicolumn{2}{|c|}{ 95\%CI } \\
\hline $\begin{array}{c}\text { Family } \\
\text { economic } \\
\text { status }\end{array}$ & $\begin{array}{c}\text { Parental } \\
\text { involvement }\end{array}$ & $\begin{array}{c}\text { Literacy } \\
\text { ability }\end{array}$ & $0.27 \times 0.94=0.25$ & 0.24 & 0.19 & 0.31 \\
& & & & & \\
\hline
\end{tabular}

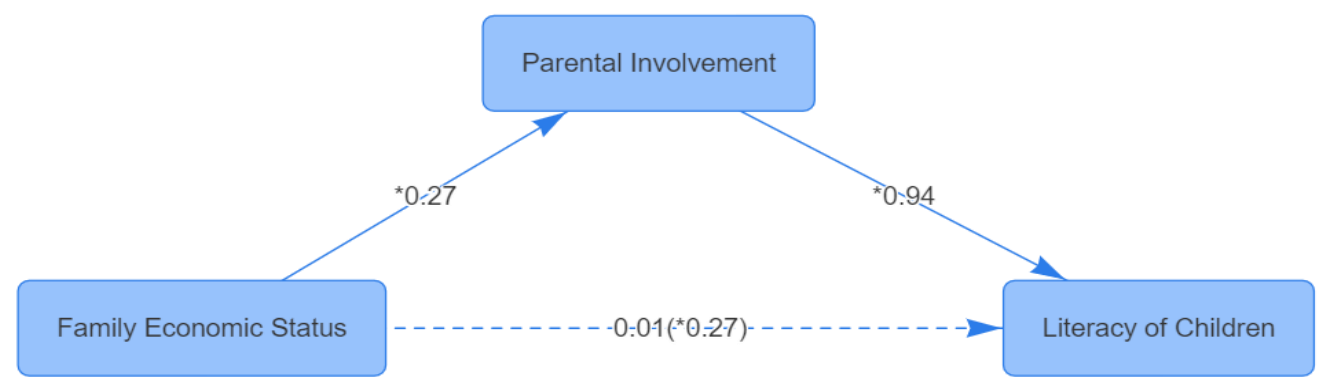

Figure1 The mediating effect of parental involvement between family economic status and literacy ability

We can learn from the Table 3 that the path coefficients of family economic status - parental involvement, parental involvement - literacy ability are significant, but the path coefficient of family economic status - literacy ability is not significant. We can learn from the Table 4 the model fits well. To further test the model, we run a Bootstrap program on the sample $(\mathrm{N}=120)$ to obtain the average path coefficient of 1000 random samples. If the coefficient $95 \%$ confidence interval $(\mathrm{CI})$ does not contain 0 , it is proved that the mediating effect of this model is significant. The mediation model of the mediating effect of parental involvement between family economic status and literacy ability is shown in figure1.

Through the results, it can be seen that parental involvement plays a significant role in the complete mediation between family economic status and literacy ability. And it can prove hypothesis 2 that parental involvement is the mediating effect between family economic status and the literacy ability of the children. In thus, the family economic status of the students surveyed promoted the improvement of children's literacy ability by affecting their parental involvement in children's education.

\section{DISCUSSION}

In this study, we take the early school-aged children as the participants, and explore the influence of their family economic status on children's literacy ability. The results showed that there was a positive correlation between family economic status and children's literacy ability, which was similar to the conclusions obtained in previous studies. Leventhal and his colleagues (2000) found that the family economic status can promote children's academic preparation and performance. In the meantime, Wang (2001) found that the better the family economic status is, the higher the mental health level of children will be. When families have good economic conditions, children will available to get better material resources. They will devote more of their cognitive resources to the development of personal cognitive ability, and will not waste cognitive resources because of other unrelated factors, such as economic constraints, negative psychological state and so on. Therefore, good family economic status can create good prerequisites for early school-aged children and lay a good foundation for the development of their cognitive abilities.

In addition, this study demonstrates that parental involvement plays a completely mediating effect in family economic status and children's literacy ability. The results are consistent with previous studies showing that family economic status indirectly affect children's cognitive development by influencing other variables. The degree of parental involvement directly affects children's cognitive ability, especially literacy ability development. In previous studies, researchers have shown that good family economic status can lead parents to involve more in the growth of their children. Good economic foundation enables parents to have more scientific parenting knowledge and experience, so that they pay more attention to the improvement of children's mental quality and personal ability. Especially in Chinese native culture, the parents of families with good economic status are more willing to participate in the daily life and study of children, and involve in the process of children's growth with scientific educational ideas. From the perspective of evolutionary psychology, in order to continue the good economic and social status of the family, parents will also put forward higher requirements for children's skills and urge them to pay 
more attention to the development of children's personal abilities. So that they are willing to invest more time, energy and material basis to the development of their children. From that, children are affected by a series of external factors and internalize these factors in the process of development to form a corresponding model, such as establishing good study habits, and then they would promote the development of their literacy ability.

The results of this study also show that family economic status and parenting style have had an impact on children's ability development as a very early age. Therefore, this is also one of the important reasons for the differences in children's subsequent abilities.

\section{CONCLUSION}

(1) There is a significant positive correlation between family economic status and the literacy development of early school-aged children;

(2) Parental involvement is a fully mediating effect in the impact of family economic status on the literacy development of early school-aged children.

\section{REFERENCES}

[1] Airan Liu. (2017). Family SES, Non-cognitive Skills and Achievement Inequality in Children's Early Life. Unpublished doctoral dissertation. University of Michiga, Michiga.

[2] Bradley, R., \& Corwyn, R., (2002). Socioeconomic Status and Child Development. Annual review of psychology, 53, 371-99.

[3] Conlon, E. G., Zimmer-Gembeck, M. J., Creed, P. A., \& Tucker, M. (2010). Family history, self-perceptions, attitudes and cognitive abilities are associated with early adolescent reading skills. Journal of Research in Reading, 29(1), 11-32.

[4] Conger, R. D., Conger, K. J., \& Martin, M. J. (2010). Socioeconomic status, family processes, and individual development. Journal of Marriage and Family, 72(3), 685-704.

[5] Duncan, G. J., Brooks-Gunn, J., \& Klebanov, P, K. (1994). Economic deprivation and early childhood development. Child Development.

[6] Epstein, J. L., Dauber, \& S. L. (1991). School programs and teacher practices of parent involvement in inner-city elementary and middle. Elementary School Journal.

[7] Galda, L. (2011). Language, literacy and the child. Orders, Harcourt Brace and Company.
[8] Henderson, R. M. (1981). Home environment and intellectual performance. Parent-child Interaction, 3-32.

[9] Hickman, C. W., Greenwood, G., \& Miller, M. D. (1995). High school parent involvement: relationships with achievement, grade level, SES, and gender. Journal of Research \& Development in Education, 28(3), 125-134.

[10] Jin Xingming. (2003). Research Progress on children's language and literacy ability. Chinese maternal and children health research, 14(005), 270-271.

[11] Leventhal, T., \& Brooks-Gunn, J. (2000). The neighborhoods they live in: the effects of neighborhood residence on child and adolescent outcomes. Psychological Bulletin, 126(2), 309-337.

[12] Li Hong, \& Shu Hua. (2009). Comparison of cognitive abilities of children with different literacy levels in preschool and primary schools. Psychological development and education, 25(003), 1-8.

[13] Li Song. (2007). Research Review on the influence of family environment on children's development. Journal of Xuchang University, (04), 143-146.

[14] Li Yan, \& Wu Weiping. (2009). Family education. Zhejiang Education Press.

[15] Li Yanfang, Guan Yijie, Lou Chunfang, et al. (2005). A review of studies on parental involvement in child development. Educational exploration, (5), 54-56.

[16] Liu Haoqiang, \& Zhang Qinglin. (2004). The impact of family economic status on the growth of children. Journal of Huaibei Coal Normal University: Social Science Edition. (4), 134-136,142.

[17] Liu Qianqian, \& Li Xiaowei. (2019). Revision of family involvement questionnaire-short form in parents of preschool children in china. Chinese Journal of Clinical Psychology, 027(001), 49-53.

[18] Mccall, R. B.. (1981). Early predictors of later IQ: the search continues. Intelligence, 5(2), 141-147.

[19] Price, J., \& Kalil, A. (2019). The effect of motherchild reading time on children's reading skills: evidence from natural within-family variation. Child Development, 90(6), e688-e702.

[20] Qin Yun \& Ge Minggui. (2011). The influence of family economic status on teenagers' reading skills. Contemporary Youth Studies, (01), 48-51. 
[21] Scribner, C., S., \& Michael. (1981). Contents: the psychology of literacy. Nature, 326(6112), 435-436.

[22] Sohr-Preston, Sara \& Scaramella, Laura \& Martin, Monica \& Neppl, Tricia \& Ontai, Lenna \& Conger, Rand. (2012). Parental Socioeconomic Status, Communication, and Children's Vocabulary Development: A Third-Generation Test of the Family Investment Model. Child development, 84.

[23] Son, S. H. (2005). Direct and indirect impact of family socioeconomic status on children's reading skills at kindergarten entry. Journal of the Korean Home Economics Association, 43(10), 39-53.

[24] Song Ranran, \& Wu Hanrong. (2008). Epidemiology of Chinese dyslexia in children. Chinese maternal and children health research, 23(11), 1505-1507.

[25] Sun Bei. (2019). The Influence of Low Family Socio-economic Status on Pupils' Reading Comprehension Ability: Intermediation and Intervention of Metacognition. Unpublished doctoral dissertation. Northwestern Normal University.
[26] Wang Maofen, Zhao Mei, \& Zhang Zhilan. (2001). The influence of family economic condition and academic achievement on mental health of senior high school students. Forum on Preventive Medicine, 7(006), 658-658.

[27] Wen Hongbo. (2005). The compilation of primary school Chinese reading ability evaluation scale. Unpublished doctoral dissertation. South China Normal University

[28] Yan Mengge, Li Hong, Hui Yi, et al. (2017). The relative importance of literacy and spoken vocabulary in the development of reading. The 20th National Psychological academic Conference-Psychology and National Mental Health Summary.

[29] Zhe, Wang, Brooke, Soden, Kirby, \& Deater-Deckard, et al. (2015). Development in reading and math in children from different ses backgrounds: the moderating role of child temperament. Developmental Science, 20.

[30] Zhou Hao. (2013). Family socioeconomic status, educational expectations, parent-child communication and child development. Youth studies, 390(03), 15-30+98. 